\title{
INTRODUCCIÓN A LA CUARTA DIMENSIÓN Y SU RELACIÓN CON LA OBRA PICTÓRICA DE KAZIMIR MALEVICH
}

Data recepción: 2013/11/16

Data aceptación: 2014/10/31

İnigo Sarriugarte Gómez

Contacto autor: inigo@inigo77.jazztel.es

Universidad del País Vasco

\section{RESUMEN}

Desde que C.H. Hinton publica su libro La Cuarta Dimensión en 1904, estos estudios comienzan a germinar tanto en ámbitos científicos y matemáticos como teosóficos, produciéndose un interesante compendio de ideas en la posterior publicación del mismo título del matemático y pensador ruso P.D. Ouspensky. La influencia del sistema Hinton-Ouspensky tendrá una notable repercusión en la obra de Malevich a partir de 1913. Los intercambios de este último con Matiuchin fueron totalmente fructíferos para la posterior aplicación de la cuarta dimensión en su trabajo. Desde los diseños de La victoria sobre el sol (1913), pasando por las propuestas alogistas hasta llegar a las obras presentadas en la Última exposición futurista: 0:10, se va gestionando un corpus formal y espacial que intenta representar un espacio cero, es decir, una nada creadora, donde los parámetros de percepción quedan invertidos con la intención de acercarnos a una esfera más espiritual que material.

Palabras clave: Malevich, Hinton, Ouspensky, Cuarta Dimensión, suprematismo

\begin{abstract}
Following the publication of C.H. Hinton's The Fourth Dimension in 1904, studies of this type began to take root both in scientific, mathematical and theosophical circles, giving rise to the interesting compendium of ideas contained in the subsequent publication of the same name by the Russian mathematician and thinker P.D. Ouspensky. The influence of the Hinton-Ouspensky System would have a significant impact on many artists but especially on the work of Kazimir Malevich from 1913. His exchanges with Matiuchin were highly productive in allowing him to apply the fourth dimension in his paintings. From the designs of Victory Over the Sun in 1913 and the first alogist proposals through to the works presented at the "Last Futurist Exhibition: 0:10", Malevich creates a formal and spatial body of work that sought to represent a zero space, a creative void where the parameters of perception are inverted as a means of moving us closer to a sphere that is more spiritual in nature than material.
\end{abstract}

Keywords: Malevich, Hinton, Ouspensky, the fourth dimension, suprematism

1. Breves apuntes sobre la Cuarta Dimensión desde las matemáticas hasta la literatura

Sin adentrarnos de manera exhaustiva en el ámbito de las ciencias exactas, simplemente esbozaremos unos breves detalles sobre esta relación. Son numerosos los filósofos y matemáticos que han trabajado esta temática, entre estos, Ludwig Schläfli (1814-1895), para quien esta dimensión era una abstracción pura, tal y como se analiza en la obra Theorie der vielfachen Kontinuität, publicada en 1852. Su interés no se centró en los polígonos, los cuales se tra- zan en el plano, ni en los poliedros del espacio tridimensional, sino en los politopos, que serían los objetos análogos a la cuarta dimensión. Mientras Platón describía los poliedros regulares en el espacio tridimensional, Schläfli los analizaba en el espacio tetradimensional. Entre sus diferentes métodos para representar objetos de la cuarta dimensión, destacó la proyección estereográfica.

Junto a este primero, también deberíamos anotar, entre otros muchos, los trabajos de Bernhard Riemann (1826-1866), centrados en la geometría de la cuarta dimensión. En relación 
con los planteamientos de estos matemáticos, P.D. Ouspensky comentó lo siguiente:

La misma idea de la cuarta dimensión debe haber estado en estrecha conexión con las matemáticas, o, para decirlo mejor, en estrecha conexión con la idea de medir el mundo. Debe haber nacido de la suposición de que, además de las tres dimensiones conocidas del espacio -longitud, latitud y altura- puede existir también una cuarta dimensión, inaccesible a nuestra percepción.

Lógicamente, la suposición de la existencia de la cuarta dimensión puede basarse en la observación de las cosas y hechos del mundo que nos rodea para lo que la medida en largo, ancho y grueso no es suficiente, o que, dicho en otras palabras, no admiten medida; porque hay cosas y hechos cuya existencia no puede dudarse, pero no pueden expresarse en ningún termino de medida. Tales son, por ejemplo, varios efectos de procesos vitales y psíquicos; tales son todas las ideas, las imágenes mentales y los recuerdos; tales son los sueños. Si los consideramos como existentes en un sentido real, objetivo, podemos suponer que tienen alguna otra dimensión además de las que conocemos nosotros, es decir, alguna extensión que nosotros no podemos medir. ${ }^{1}$

Igualmente, debemos destacar a C.H. Hinton (1853-1907), con su famoso artículo What is the Fourth Dimension? de 1880, planteando que los puntos que se desplazaban a lo largo de las tres dimensiones podían asumirse como secciones consecutivas de líneas cuatridimensionales, cruzando un plano tridimensional, una teoría que se adelantó al planteamiento de línea de universo y del tiempo como cuarta dimensión. No obstante, esto último no fue planteado por Hinton de manera directa, ya que el texto abordaba únicamente la posibilidad de una cuarta dimensión espacial, que más adelante tomaría forma en la Teoría de la Relatividad de Einstein.

Debemos recordar que Hinton utilizó una serie de cubos coloreados mediante cuyo análisis planteaba recrear el espacio tetradimensional. Posteriormente, en abril de 1904, C.H. Hinton publica el famoso libro La cuarta dimensión, basado en conceptos que habían sido ya tratados en 1880. Sobre los métodos de este último para captar mejor el concepto de la cuarta dimensión, el matemático y pensador ruso P.D. Ouspensky realiza la siguiente anotación:
La idea fundamental que guió a Hinton en la creación de su método de ejercicios es que para despertar la conciencia superior se requiere de la expulsión del yo propio en la representación y conocimiento del mundo, es decir, el acostumbramiento de uno mismo en el conocimiento y concepción del mundo, no desde un punto de vista personal (que es como generalmente lo conocemos y lo concebimos), sino tal como es. Para ello es necesario, antes que nada, aprender a representar las cosas no como aparecen ante nosotros, sino como ellas son, aun cuando fuera solamente en un sentido geométrico. A partir de esto debe desarrollarse la capacidad de conocerlas, es decir, de verlas tal como son, también desde otros puntos de vista, además del geométrico. ${ }^{2}$

Igualmente, añade lo siguiente sobre el matemático británico: "Hinton llama metageometría al sistema de investigación del espacio superior, y conecta con la metageometria los nombres de Lobachevsky, Gauss y otros investigadores de la geometría no-euclidiana." 3

Como es sabido, P.D. Ouspensky parte del libro de C.H. Hinton para escribir su obra titulada La cuarta dimensión (San Petersburgo, 1909), donde las ciencias físicas y los planteamientos técnico-científicos se insertaban junto a planteamientos de la psicología moral y filosófica. En este sentido, para Andréi Nakov, "la sólida cultura científica (principalmente matemática) que sostiene el pensamiento de Uspenski le permite aproximarse sin prejuicios a la concepción de una cuarta dimensión de la conciencia y del intelecto humanos."4

Aunque se aprecian diferencias en las teorías de ambos matemáticos, como anota Raúl Ibáñez: "Para Hinton y Ouspensky, la cuarta dimensión no es sólo un concepto espacial, sino también un tipo de conocimiento, una toma de consciencia de una realidad superior. Para ellos el estudio matemático de la cuarta dimensión lleva de forma natural a las creencias místicas, que de forma sencilla pueden resumirse como: Todo es Uno, y el Uno es incognoscible. " 5 Ouspensky había dejado muy claro que actualmente no somos capaces de percibir la cuarta dimensión, lo que no quiere decir que no exista, al igual que para un animal sólo existe el mundo en forma bidimensional. Ouspensky, en la línea de otros intelectuales, como Claude Bragdon, se oponía 
a las recetas más mecanicistas y formalistas de las ciencias, de hecho en su defensa de la filosofía del hiperespacio, apuesta con claridad por la existencia de una cuarta dimensión del espacio.

Otro científico de interés, bajo esta misma ruta de investigación, ha sido el físico Michio Kaku (1947), co-creador de la String Field Theory, una rama de la teoría de cuerdas, quien además ha escrito varios libros en relación al hiperespacio bajo la influencia del budismo y el cristianismo, entendiendo que el mundo no tiene ni principio ni fin, a pesar de que bajo la influencia del cristianismo se asume la noción de un universo con principio y fin.

Dentro del apartado literario, la cuarta dimensión ha disfrutado de un notable protagonismo. Debemos anotar especialmente la fecha de 1884, cuando Edwin Abbot redacta la novela titulada Planilandia: una novela de muchas dimensiones por un cuadrado, donde se describe un mundo bidimensional habitado por figuras geométricas planas (círculos, polígonos, cuadrados y líneas). En esta novela, se aborda el estudio de los espacios en progresión en relación con su dimensión. No obstante, estas ideas no son tan originales, como se pensaban, ya que anteriormente habían sido perfiladas en La República (libro VII) de Platón, donde se describían espacios en progresión y la idea de la analogía dimensional; al igual que conecta directamente con el noúmeno kantiano. De hecho, el mito de la caverna fue entendido como una analogía de la posibilidad de múltiples dimensiones.

En dicha novela, en el momento que un ser de dimensión superior, caso de Lord Esfera, se muestra en su universo, los habitantes de este mundo planimétrico se muestran incapaces de percibirlo en su totalidad, tan solo ven círculos que se van ensanchando y encogiendo (es decir, secciones de la esfera a medida que atraviesa el plano). Lo mismo ocurriría, se cree, si un ser de una cuarta dimensión se manifestara en nuestro universo, ya que veríamos un amasijo abstracto tridimensional en constante transformación. A su vez, ese ser tetradimensional vería nuestro mundo como un cuadro cubista, desde todos los puntos de vista posibles simultáneamente.

También, junto a las alusiones relacionadas con esta temática por parte de Marcel Proust en la novela En busca del tiempo perdido (1913) y Ezra Pound en el Canto 49 (1937), encontramos anteriormente a otros novelistas de ficción, como H.G.Wells cuando utiliza la cuarta dimensión (en este caso temporal, no espacial) para hablar de la lucha de clases en su novela La maquina del tiempo (1895) o con El hombre invisible (1897), continuando la tradición de d'Alembert y tratando el tiempo como la cuarta dimensión. Por último, no podemos olvidarnos de los poemas cubistas de Max Weber y los caligramas de Apollinaire, así como la llamativa y visual poesía de Gertrude Stein, redactada bajo la influencia de Apollinaire, aunque esto fuera desmentido posteriormente en una entrevista que se le realiza en la revista Atlantic Monthly en 1935.

\section{La cuarta dimensión y su relación con los artistas modernos}

Para Linda Dalrymple Henderson, "la cuarta dimensión fue primeramente un símbolo de liberación de los artistas" ${ }^{\prime 6}$, lo que les permitió alejarse de la realidad visual y rechazar completamente el sistema de perspectiva única. En este sentido, las ideas de Hinton habían tenido una relevante repercusión sobre los planteamientos cubistas y el propio Duchamp, aunque este último más interesado por la novela del francés Gaston de Pawlovski: Viaje a la cuarta dimensión (1912), que conoce y posteriormente se vincula con su Gran vidrio.

A principios del siglo $\mathrm{XX}$, las artes quedan influenciadas por dos interpretaciones relacionadas con la dimensionalidad superior. La primera como concepto geométrico espacial, que es aparente en el temprano cubismo al visualizar todos los lados de un objeto simultáneamente, mientras que por otra parte se vuelve una clase de código místico, empleado para justificar la experimentación vanguardista. De este modo, Apollinaire fue uno de los primeros que escribió sobre la cuarta dimensión en las artes con su ensayo Les peintres cubistes de 1913, quedando la cuarta dimensión asociada inicialmente a las formas facetadas y los múltiples puntos de vista del cubismo. Apollinaire en esta anterior obra literaria definió la cuarta dimensión como "la inmensidad del espacio eternizándose en todas dimensiones en un momento determinado."7 
Posteriormente, dicha dimensión también sería identificada con la gravedad (Marcel Duchamp, Morton Schamberg), así como con la antigravedad (Malevich, Lissitzky, van Doesburg) ${ }^{8}$, etc.

Los teóricos del cubismo Albert Gleizes y Jean Metzinger, para abordar el tema de la cuarta dimensión, estudiaron geometría con el matemático francés Maurice Princet. Su participaron en el Grupo Puteaux les permitió conocer de primera mano las teorías de la cuarta dimensión, como otras muchas disciplinas filosóficas y esotéricas, que tanto atraían a estos pintores. Los artistas vinculados a este grupo (Gleizes, Metzinger, Juan Gris, Delaunay, Leger, Duchamp-Villon, así como Picabia y Duchamp) y el propio Maurice Princet mostraron un interés patente por esta temática. Con este fin, resultó esencial, junto a las teorías de Princet, la lectura de los tratados matemáticos y de geometría de $\mathrm{E}$. Jouffret en Traité élémentaire de géometrie à quatre dimensions (1903) y Melánges de géométrie à quatre dimensions (1906), entre otros.

Si Picasso había recabado en la búsqueda de un punto de vista variable para poseer el objeto en su totalidad, el pintor ruso Malevich, por el contrario, defendía que lo que estaban desarrollando Picasso y Braque no era mas que destruir la identidad de las cosas, afirmando que "gracias a su pulverización del objeto, los cubistas abandonan el campo de la objetividad. "9 Independientemente de estas opiniones del fundador del suprematismo, ciertamente el cubismo había roto con la visión de las tres dimensiones, acercándose a los postulados que se defendían sobre la cuarta dimensión, es decir, aquella que permitía ver una figura en su globalidad. Por consiguiente, se elimina la perspectiva unívoca y se utiliza la multiplicidad de planos, pudiendo analizar el objeto representado desde varias perspectivas simultáneas, al igual que su interior.

La simultaneidad había sido la manera más directa para los cubistas de representar y analizar el sentido de la cuarta dimensión en la pintura. Dentro del cubismo, Juan Gris sentía una declarada fascinación por las especulaciones matemáticas de Princet que impulsaron al pintor madrileño a la búsqueda y estudio de la cuarta dimensión, como posteriormente se podría de- mostrar en la conferencia que impartió en la Sorbona con el título Sur Les possibilités de la peinture. Para Metzinger, la cuarta dimensión era un pretexto para que el artista se desentendiese de las relaciones abstractas entre los objetos y analizara lo que incide en la mente del artista. En definitiva, la cuarta dimensión agrupa todas las características del espacio cubista, por ejemplo, la percepción simultánea, el protagonismo de los volúmenes y el dinamismo tensional que se produce por el efecto de trasgresión del espacio tradicional de conformación euclidiano. Por otra parte, Francastel lo considera como el elemento que introduce el tiempo en el cuadro, teniendo en cuenta el debate que había surgido en relación al espacio-tiempo generado más adelante por la teoría de la relatividad.

La idea del espacio-tiempo tetradimensional está muy conexionada con las nociones de velocidad y movimiento, características que serían analizadas por los artistas después del desarrollo de la fotografía. Entre los primeros ensayos para su análisis, como precedentes debemos anotar la introducción de la dimensión temporal en las imágenes, con la creación de instrumentos muy exóticos, como el electrotachyscope, phenakistoscope, praxinoscope y el zoopraxiscope, aparato empleado por Eadweard Muybridge (18301904). Este último junto con Etienne Jules Marey y el pintor norteamericano Thomas Eakins, quienes capturaron imágenes sucesivas del galope de un caballo, inventaron el zoopraxiscope para reproducir las escenas en secuencia sucesiva, generando de este modo el efecto del movimiento. Pero, realmente debemos destacar a los futuristas, con su obsesión por la representación de la velocidad, ampliando las reminiscencias de las fotografías secuenciales de Marey. Sin embargo, para Andréi Nakov: "Los futuristas italianos, guiados por unas consideraciones puramente teóricas y deudoras de una herencia predominantemente literaria (Marinetti), eran por su parte incapaces de cruzar el umbral simbólico de una teoría evasiva en lo que se refiere a la articulación formal de los medios plásticos. La inoperancia pictórica de sus ideas sintéticas, ligadas al idealismo espiritual de la simultaneidad, hace imposibles de realizar, con los únicos medios de la pintura narrativa de los futuristas, los nuevos conjuntos preconizados por Apollinaire." 10 
También, resultan de interés los siguientes comentarios del pintor ruso Malevich: "Claro está, se produce una situación seria: la creación de la cultura sobre unos cimientos de tres dimensiones, amenazada por una muerte inevitable, muerte de sus formas, dividiéndose/o pulverizándose/ en el espacio del movimiento. El hombre accede a una nueva circunstancia de tiempo donde no puede, desde luego, construir la antigüedad de la tridimensionalidad, ya que el volumen se encuentra en el tiempo y no puede ser reforzado sobre cimientos." 11

Por otro lado, Larionov y Goncharova describieron en su manifiesto Rayonistas y futuristas (1913) el tratamiento rayonista de la siguiente manera:

A los objetos que vemos en la vida no les corresponde aquí ningún papel, pero aquí puede mostrarse de modo óptimo lo que constituye la esencia de la misma pintura: la combinación de color, su saturación, la relación de las masas coloreadas, la profanidad, la textura....El cuadro... provoca una sensación de lo extra-temporal o de lo espacial. En él se produce la sensación de lo que podría llamarse la cuarta dimensión, porque su longitud, aliento y densidad de la capa de pintura son los únicos signos del mundo exterior...A estas alturas surge una especie de pintura que puede dominarse mediante el seguimiento precisamente de las leyes de los colores y su trasferencia al lienzo. ${ }^{12}$

Además de estos ejemplos anteriores, son numerosos los movimientos que de una manera u otra han tratado este tema, caso del grupo Der Blau Reiter, el constructivismo, el círculo cercano a Stieglitz y Arensberg en Estados Unidos, así como numerosos artistas, entre los que se encuentran Kupka, Lissitzky y van Doesburg, entre otros. Incluso, la Bauhaus se vio influenciada a través del interés mostrado por algunos de sus docentes, como Kandinsky y van Doesburg.

Por otro lado, como es sabido en los escritos de Mondrian las esencias platónicas convergen con el concepto hegeliano del todo ${ }^{13}$. Por ejemplo, para Hegel "nada puede ser realmente verdadero a menos que la Realidad sea un todo." ${ }^{14}$ En este sentido, el mundo entendido como elementos separados y desconexionados no representa más que una ilusión y la realidad de las cosas separadas consiste únicamente en la relación con el todo. De ahí, que las pinturas de Mondrian en base a sus campos cromáticos y líneas que parecen extenderse más allá de los límites del lienzo se remitan a esta misma idea. En general, hay una idea del continuum espacial infinito, como manifestación de lo absoluto, aspectos que ya habían sido tratados por el platonismo, el noúmeno kantiano y el absoluto hegeliano y prácticamente todas las enseñanzas budistas. Incluso, ese todo como la nada y el absoluto se entiende en los preceptos malevichianos como el desierto: "Decisiva es, en cambio, la sensibilidad; a través de ella el arte llega a la representación sin objetos, al suprematismo. Llega a un desierto donde nada es reconocible, excepto la sensibilidad." 15

No obstante, también hay voces críticas a todas estas relaciones, siendo una de ellas la de Donald Kuspit al comentar:

Es sin duda un error natural de erudito suponer que cuando los pioneros del arte abstracto hablaban de la cuarta dimensión en sus obras -algo que hacian con frecuencia- sabían de qué hablaban. Pero lo no sabían. El concepto tenía para ellos un significado y un uso narcisista y no realista. Como los mediadores de la nueva realidad de la cuarta dimensión, los artistas abstractos imaginaron que tenían poder sobre las tres dimensiones de la vieja realidad: se equivocaban. En general, los pioneros del arte abstracto experimentaron lo que Jung llamó una crisis de individualización. A través de la no objetividad intentaron reconciliar, en palabras de Jung, el conflicto entre sus arcaicas imágenes de yoidad omnipresente y las exigencias de las normas sociales, es decir, la nueva concepción normativa de la realidad como dotada de una cuarta dimensión ${ }^{16}$.

En una línea similar, se han posicionado otros autores, como Ángel González García: "Convencidos unos y otros de la superioridad de lo que se traían entre manos, suprematistas y super-realistas han vuelto a coincidir en eso de hacerse los misteriosos, como si todos ellos estuvieran en el secreto de cosas que el común de los mortales ni siquiera sospecha, y a coincidir además -itodo tiene un precio!- en haber sido presa fácil de embaucadores y charlatanes." 17

Para finales de los años 20, la teoría einsteineana del espacio-tiempo acabó arrinconando la 
moda de la cuarta dimensión en los ámbitos artísticos. Parecía que se optaba por dejar de lado una perspectiva de la ciencia bajo un formato más abierto a las especulaciones metafísicas por otra de carácter más limitada. Únicamente, serán los surrealistas los que continuarán haciendo referencia a esta, como un acto de rebeldía y reivindicación de lo absurdo y entre ellos especialmente Salvador Dalí, que llegaría a pintar un tesserat o hipercubo (cubo de cuatro dimensiones) proyectado en su famoso Corpus Hypercubus (1954), con la intención de crear la imagen de un Cristo de dimensión superior, siendo proyectado como hombre en la tierra. El concepto de teseracto fue acuñado por C.H.Hinton como sistema de visualización de la geometría en varias dimensiones. Dalí mostró un visible interés por el 3D de las holografías y la estereoscopia, como elementos que trasladaban al espectador a una dimensión superior, de hecho, estos aspectos los había intuido en De Nova Geometria (1299) de Ramón Llull y Discurso sobre la figura cúbica (alrededor de 1585) de Juan de Herrera.

\section{Búsqueda de fuentes para el estudio de la Cuarta Dimensión en la obra de Ma- levich}

Los primeros años del siglo $\mathrm{XX}$, en los que principalmente desarrolla su obra el artista ruso Malevich vienen marcados por una avalancha de estudios astrológicos y teosóficos vinculados a los escritos de H.P. Blavatsky. Para el investigador Andréi Nakov:

La exuberancia metafórica del lenguaje malevichiano se inscribe perfectamente en la herencia de una tradición simbólica eslava -y sobre todo polaca- fin de siglo, filón patético y visionario con el que se pueden relacionar tanto los nombres de Wyspianski, Przybyszewski y Witkiewicz como los de Berdiaiev, Uspenski y Zamiatin. Sin embargo, con la sola excepción de Uspenski, Malevich no comparte con los autores citados el drama de su pesimismo escatológico: para él la aventura humana se inscribe en un porvenir que no puede ser más optimista, al multiplicarse las oportunidades del hombre gracias a los nuevos poderes que ha adquirido sobre la materia, sobre unos mundos nuevos que será capaz de fabricar cada día y, en último lugar -y ante todo- sobre sí mismo, sobre sus propias capacidades de comprensión y de invención. ${ }^{18}$
No obstante, será el compositor y pintor Mijail Matiushin, amigo cercano de Malevich, quien lo inicia en el tratado de La cuarta dimensión de Howard Hinton. Por otro lado, Malevich también se sitúa en la tradición mística de Ruysbroeck, Boehme y Lao-Tse, lo que le conduce a asumir el concepto de la nada como un vacío creador.

Es bajo este contexto intelectual y filosófico cuando se impulsan las investigaciones de corte abstracto, tal y como ocurre con Malevich al conectar con las teorías de Hinton, Ouspensky y los diagramas de Bragdon, lo que conlleva la realización de una representación espacial libre de gravedad, donde las distintas figuras geométricas aparecen levitando en fondos neutros, mostrando la existencia de un cimiento infinito y la ruptura total con la perspectiva tridimensional, en lo que sería la creación pura del arte, es decir, el arte no-objetivo malevichiano. En este sentido, el estilo de la no objetividad de Malevich fue la deuda más directa de la cuarta dimensión, tal y como lo han defendido varios autores, entre ellos especialmente Linda Dalrymple Henderson. De hecho, para Malevich, no basta con ver; también hay que conocer, planteamiento que también iba dirigido a los cubistas, como iniciadores de una tarea que más adelante tuvieron que terminar los suprematistas, siendo necesario dejar a un lado lo que se ve para profundizar en lo que hay que conocer, ya que las apariencias engañan y no todo lo que ve el ojo es real.

En los escritos de Hinton y Malevich, hay conexiones sobre la cuarta dimensión en relación con las formas geométricas y el precepto para escapar de la gravedad. También, Ouspensky había empleado la analogía de un mundo bidimensional con figuras geométricas pasando a través de éste para explorar la primera percepción del ser inferior de una dimensión superior en tiempo y movimiento. Por otro lado, resulta de interés comparar las formas proto-suprematistas (Fig. 1) que aparecen en el libro de Claude Bragdon ${ }^{19}$ titulado Man the Square (1912) con la obra de Malevich, sin que estas hayan sido la referencia inicial de las pinturas suprematistas del artista ruso. Incluso, el propio Ouspensky tenía una copia de este libro.

Dentro de estos contextos de asentamiento de bases filosóficas y espirituales, también de- 
bemos anotar la relevancia del libro titulado The Other Side of Death (1903) de C.W. Leadbeater $^{20}$, que se unía al pensamiento de C.H. Hinton. De hecho, Leadbeater había visto en el sistema de ejercicios propuestos por Hinton la posibilidad para desarrollar la visión astral ${ }^{21}$. En la línea de Leadbeater, Ouspensky anota lo siguiente:

Si la cuarta dimensión existe y nosotros poseemos solo tres, esto quiere decir que no tenemos existencia real, que existimos solamente en la imaginación de alguien, y que todos nuestros pensamientos, sentimientos y experiencias se realizan en la mente de algún otro ser superior, que nos representa mentalmente. No somos sino productos de su mente $y$ todo nuestro universo no es sino un mundo artificial creado por su fantasía.

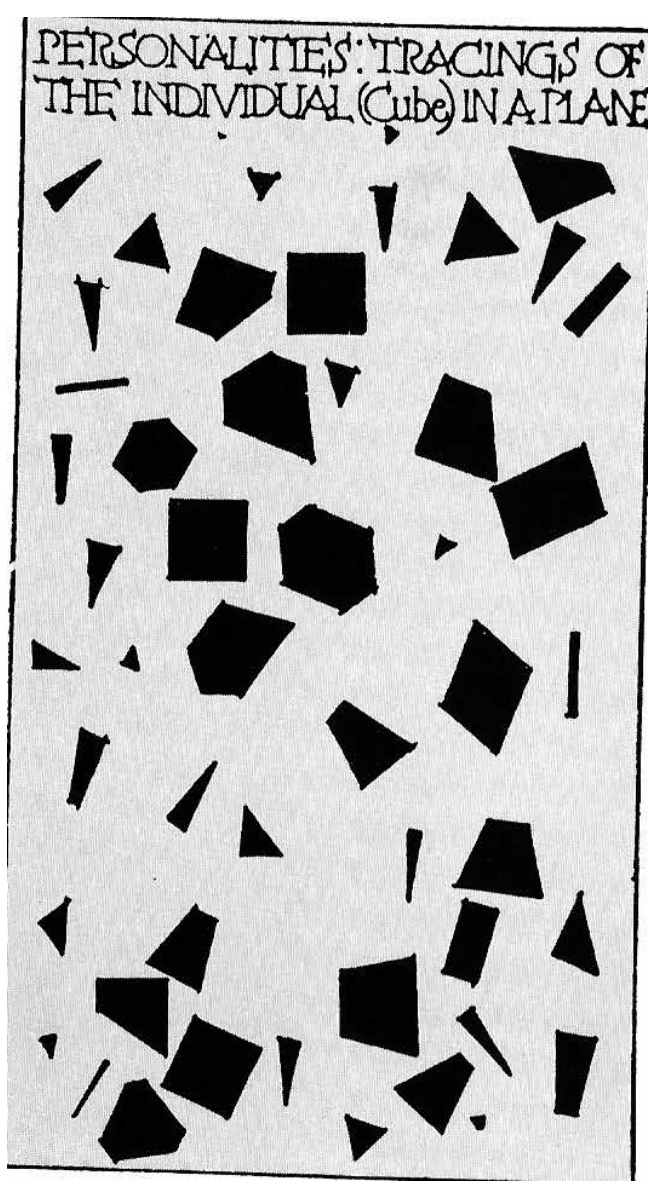

Fig. 1. Claude Bragdon, Personalities: Tracings of the Individual (Cube) in a Plane, del libro Man the Square: A Higher Space Parable - 1912
Si no queremos aceptar esto debemos admitir entonces que nosotros somos seres de cuatro dimensiones. ${ }^{22}$

Este tipo de estudios, temáticas y planteamientos metafísicos resultaron algo habitual en las tertulias teosóficas de numerosas capitales europeas entre 1911 y 1912. Debemos destacar la publicación en 1911 del artículo titulado L'Esprit et l'espace: La Quatrième Dimension en el periódico Le Théosophe, siendo su autor L. Revel, donde se recogen los puntos de vista de Leadbeater. En las siguientes líneas vemos la importancia de las ideas de Revel para su posterior asimilación artística: "Las percepciones de un mundo más sutil interpenetrando aquellos de un mundo inferior debe ser el primer resultado en una expansión de las nociones de la mente sobre la dimensiones del espacio, y después en una apertura de una visión más interior, como una visión interna que penetra a través de los objetos." ${ }^{23}$ En una línea similar, Ouspensky añade que "El Profesor Zollner desarrolló la teoría de la cuarta dimensión a partir de sus observaciones de los fenómenos mediumnísticos, especialmente de los fenómenos de la llamada materialización. Pero sus observaciones se han considerado desde hace mucho tiempo como dudosas debido al hecho comprobado de la verificación no suficientemente estricta de sus experimentos (Podmore y Hislop)." 24 Posteriormente, en 1912, Editions Théosophiques publica Quatriéme Dimension de A. de Noircarme, donde se llega a hablar del hipercubo tetradimensional.

La influencia del sistema de Hinton-Uspenski se aprecie especialmente en los años 19131915, confirmándose como el periodo en donde Malevich plantea el nacimiento de sus ideas suprematistas. De hecho, durante el año 1913 se producen los principales intercambios con Matiuchin. Por otra parte, debemos anotar que todos los temas abordados por Matiuchin estaban muy relacionados con los planteamientos de Ouspenski. Las preocupaciones esféricas del matemático ruso Ouspenski, por ejemplo, se verán más adelante, en 1919-1926, reflejadas en la teoría de la visión ensanchada ${ }^{25}$, que desarrollará el propio Matiuchin.

El interés de Malevich y Matiuchin por la cuarta dimensión siguió vivo en los años 20 , en 
unos años donde se empezaba a imponer las teorías de Einstein, incorporando la definición de esta dimensión como tiempo en su teoría artística. Posteriormente, a partir de 1919, aparece un nuevo interés en sus escritos, tal y como aparece en el texto Suprematismo: 34 dibujos, asumiéndose las formas suprematistas en términos de física.

Igualmente, en relación con la palabra suprematismo, esta comienza a aparecer en los escritos malevichianos de los años 1913-15, a modo de constante terminológica de lo supranatural dentro de la estructura mística del pensamiento de Malevich, con el objetivo de afirmar un estadio superior de la existencia del pensamiento.

Malevich a partir de 1919 va abandonando la pintura a favor de la actividad teórica, la enseñanza y la producción de textos. Podemos considerar que el manifiesto de 1923 da por finalizado un período de importantes planteamientos teleológicos, de la misma manera que Del cubismo y el futurismo al suprematismo (1915) suponía el pistoletazo de salida para asentar las bases espirituales de una nueva concepción de la pintura. Estos dos manifiestos de 1915 y 1923 marcan el periodo más productivo e interesante en relación con los descubrimientos suprematistas de Malevich, manteniendo la continuidad de las diferentes bases apriorísticas que mantendrá toda su vida. En este sentido, para John Golding, "ese popurrí especulativo es lo que hace que el Manifiesto suprematista sea tan apasionante, pero también lo que lo hace difícil y desconcertante. Sin embargo, si no lo vemos como un credo estético o filosófico coherente sino tan sólo como una especulación apocalíptica sobre la naturaleza de la pintura y la forma en que podría evolucionar en manos de Malevich y de sus potenciales seguidores (y éstos pronto iban a cerrar filas detrás de él), el manifiesto resulta más accesible." 26

Los escritos de Malevich vienen articulados por referentes constantes al poder creador de la nada, entendido como generador de vida y fuente universal de creación, mientras a la vez se plantea un claro rechazo al mundo material, esta vez entendido como algo finito, no creador y sin ninguna posibilidad de desarrollo, junto con otros parámetros especulativos, que estaban extraídos de las corrientes místicas del pensamiento occidental (Ouspensky, Boehme, Maestro Eckart, Ruysbroeck) y oriental (textos budistas y Lao-Tsé).

Malevich vio su pensamiento condenado al ostracismo y a la falta de comprensión, especialmente a partir del año 1923, por la clase dirigente de su país. Tal y como lo expresaba el propio artista:

La sociedad no ha deducido de ello que no conozca el valor efectivo de las cosas; $y$ este hecho se ha convertido en la causa de los crónicos fracasos de cualquier practicidad. Los seres humanos podrían llegar a un verdadero y absoluto orden en sus relaciones reciprocas solo si quisieran formarlo y realizarlo en el espíritu de los valores inmortales. Después de todo esto, es evidente que el elemento artístico debería ser tomado en consideración, bajo todos los puntos de vista, como algo decisivo; al no ser así, las relaciones humanas estarán dominadas en todos los campos de la vida, no tanto por la anhelada tranquilidad del orden absoluto, cuanto por la confusión de los ordenes provisionales, ya que el orden provisional viene determinado por los criterios de los conocimientos contemporáneos, y tales criterios, como sabemos, son los que mas varían. ${ }^{27}$

\section{Plasmación de la Cuarta Dimensión en la obra pictórica de Malevich}

Los primeros acercamientos de Malevich aparecen en 1913 con la exposición celebrada en San Petersburgo junto al grupo vanguardista Union of Youth, donde el artista mostraba sus primeros trabajos alógicos relacionados con el realismo transracional. Para José María Faerna, "Lo alógico marcó la transición de los estilos cezanesco y cubista de Malevich al suprematismo, la abstracción más radical de la pintura vanguardista." 28

Durante 1914, Malevich combinó formas geométricas con objetos reconocibles en ciertas pinturas alogistas, caso de Mujer en la columna de los carteles (Fig. 2). En estas pinturas alogistas, que dominan su arte hasta 1914, Malevich retoma el contenido de la cuarta dimensión, adoptando la literatura filosófica ouspenskyana de Kruchenykh para la pintura. En trabajos como Un inglés en Moscú (1914) (Fig. 3), se muestra una nueva perspectiva incorrecta, donde se ob- 
serva un solapamiento irracional de formas que varían ilógicamente en tamaño. Las pinturas alogistas son en cierto sentido la contraparte de las palabras zaum y la sintaxis ilógica de Kruchenykh. Para Andréi Nakov, en relación con las obras alógicas: "La aparición de esta nueva categoría de obras señala el importante cambio ocurrido en la concepción malevichiana de la pintura. Los criterios de una nueva lógica del sentido de la imagen, inspirada por los postulados transracionales, cuyo paradigma hay que buscar en el sistema lógico de Uspenski, sitúan la pintura moderna en un camino analítico que permite evitar el atolladero formal del discurso cubista, cuyos límites puramente estéticos, por estrechamente compositivos, había denunciado claramente Malevich." 29

Anteriormente, en el verano de 1913, Malevich había diseñado la escenografía y el vestuario para la ópera La victoria sobre el sol, compuesta por Mijail Matiushin con libreto de Alexei Kroutchenykh. La ópera era una metáfora del ocaso de los tiempos antiguos, refiriéndose el título a la victoria sobre los conceptos, creencias y certezas del antiguo sol de la razón.

Estos trabajos son el germen de las posteriores figuras geométricas que compondrán el suprematismo, especialmente la figura del cuadrado, que aparece como un tropo a lo largo de su obra. Si la habilidad de los escritos de Krchenykh para evocar una nueva forma de consciencia alcanzaba su cenit en esta ópera, Malevich al mismo tiempo comenzaba a experimentar con formas geométricas con las que finalmente generaría un puente para entender la cuarta dimensión en el suprematismo de 1915.

En el telón abstracto de fondo de color negro usado para el primer acto, escena 1, se podía observar un gran cuadrado, siendo el precedente del posterior Cuadrado negro. Este negro telón era una representación simbólica de una especie de eclipse de los viejos tiempos para dar paso a una nueva época, que más tarde tomaría forma incluso en los escritos del pintor: "el cataclismo del mundo antiguo es inevitable, la época del suprematismo en tanto que mundo no objetivo ha hecho que se derrumbe el paso de la materia y ha desbaratado el orden de marcha de la vieja razón." 30

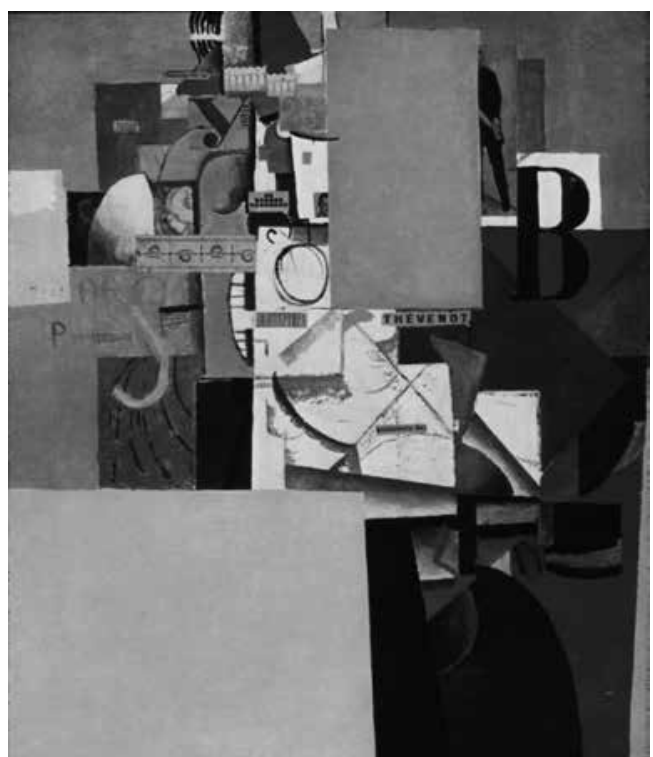

Fig. 2. Malevich, Mujer en la columna de los carteles - 1914.

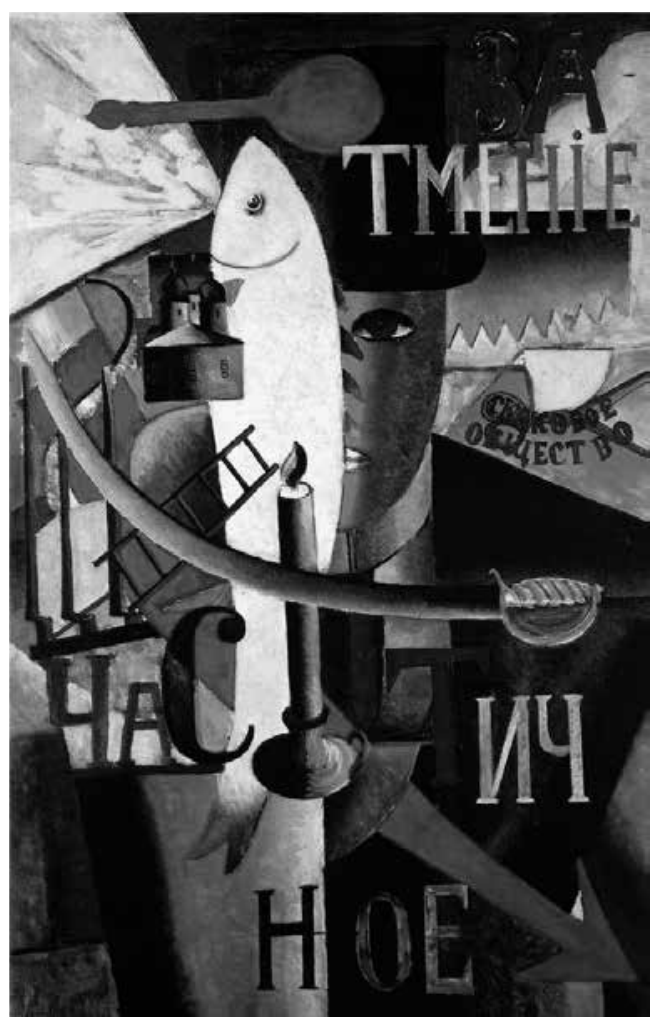

Fig. 3. Malevich, Un inglés en Moscú - 1914 
Incluso, el uso del color en dicho telón será una de las posteriores bases del suprematismo, tal y como lo explica Malevich: "He mencionado que en el suprematismo el negro y el blanco juegan el papel de la energía que descubre la forma. De hecho, esto sólo concierne a la construcción sobre el lienzo de los proyectos suprematistas en volumen; efectivamente, en la acción real, táctil, esto no es así porque es la luz la que revela la forma. En las formas del suprematismo real sólo permanecen el negro y el blanco y de ellos deriva toda la gradación de la energía de los materiales, es decir que llegará la época en que a los nuevos materiales se les prive de color y tonos." ${ }^{31}$

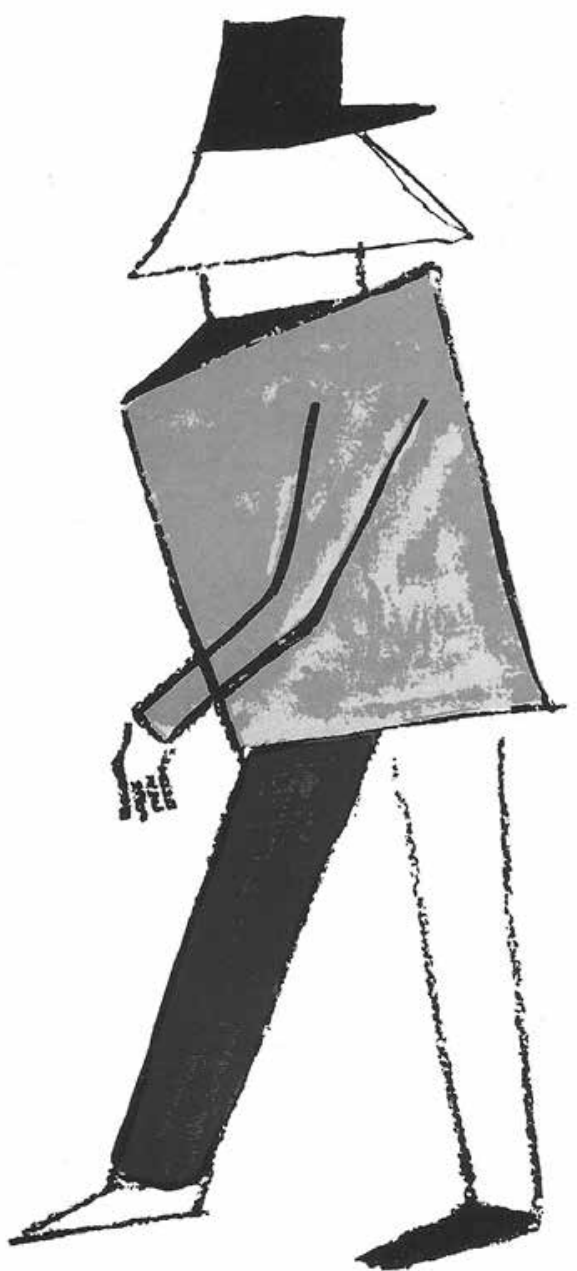

Fig. 4a. Malevich, Diseño de vestuario para Victoria sobre el Sol- 1913
Aunque la mayoría de los experimentos geométricos de 1913 no tuvieron una conexión directa con la cuarta dimensión, sin embargo, uno de los diseños de la Victoria sobre el Sol, en el segundo acto donde se representa una casa, así como la pintura titulada Instrumento musical - Lámpara de 1913, parecen incorporar la imagen popular del hipercubo tetradimensional, es decir, el diseño que Hinton había empleado en la construcción del teseracto, siendo muy apropiado el uso de esta estructura por Malevich para el segundo acto (Figs. 4a, 4b, 5, 6 y 7).

Durante 1914, comienza a adentrarse de una manera más decidida en el océano cósmico y de consciencia ouspenskyano, siendo ese año cuando aparece el libro La Cuarta Dimensión de Ouspensky. La primera serie de lienzos suprematistas es realizada en el verano de 1915, pero se mantienen en secreto hasta la Última exposición futurista: 0:10. En dicha muestra, el artista había

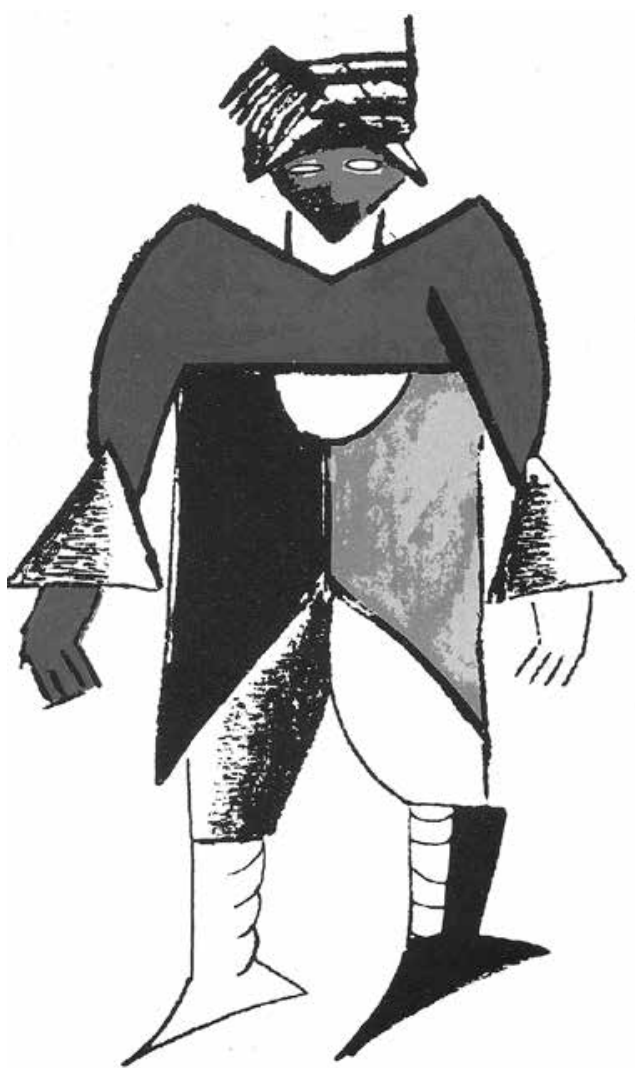

Fig. 4b. Malevich, Diseño de vestuario para Victoria sobre el Sol - 1913 


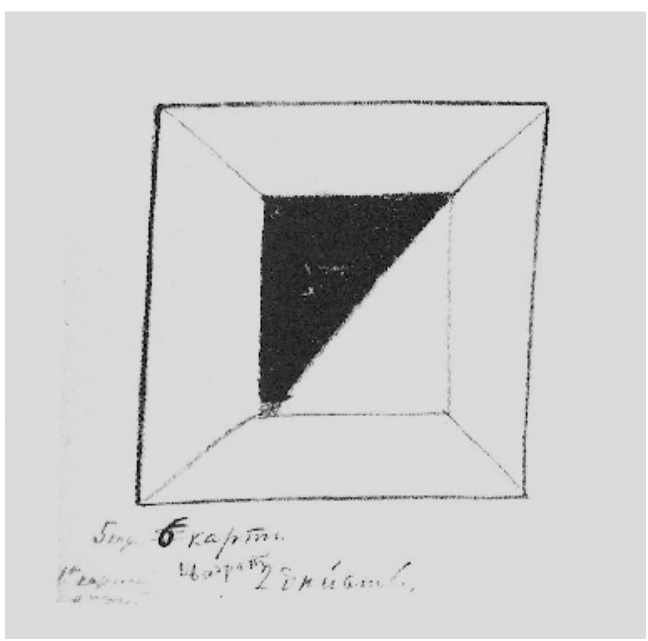

Fig. 5. Malevich, Diseño para telón en la Victoria sobre el Sol - 1913

puesto una serie de carteles en las paredes entre los cuadros, confirmando las ideas contenidas en el manifiesto de diciembre de 1915, donde se podía leer Supremacía de la pintura. Las 39 obras presentadas en esta exposición fueron divididas entre los subtítulos masas de color en la segunda dimensión y masas de color en la cuarta dimensión, destacando dentro de esta última: Realismo pictórico de un futbolista-Masas de color en la cuarta dimensión (1915) y Realismo pictórico de chico con mochila-Masas de color en la cuarta dimensión (1915) (Figs. 8 y 9).

Estos subtítulos indicaban que Malevich pensaba en su espacio pictórico suprematista en términos tanto de dos y cuatro dimensiones, ha-

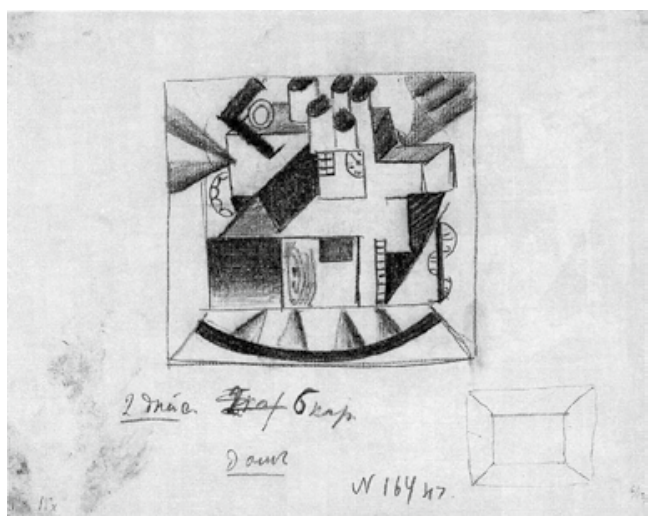

Fig. 6. Malevich, Diseño para escenografía del segundo acto en la Victoria sobre el Sol - 1913

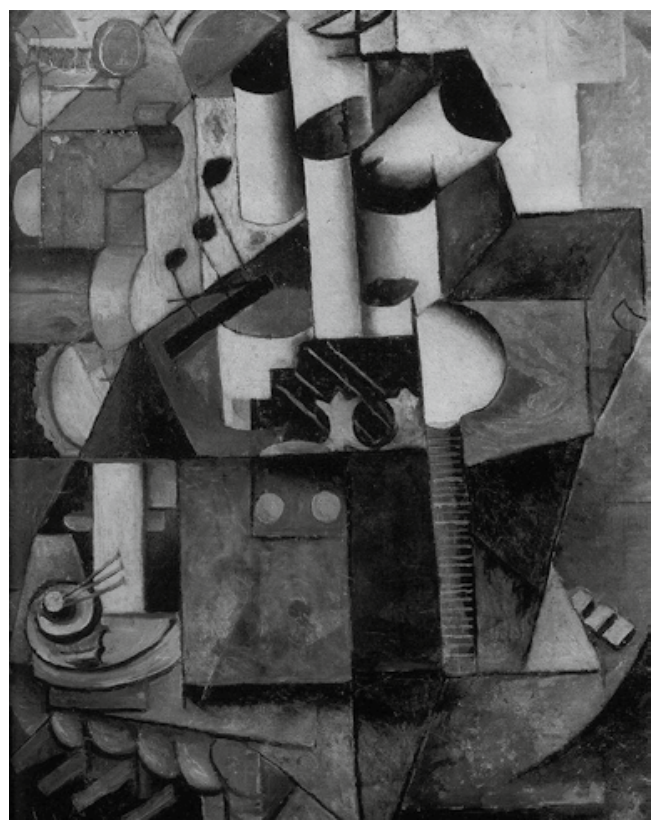

Fig. 7. Malevich, Instrumento musical - Lámpara - 1913
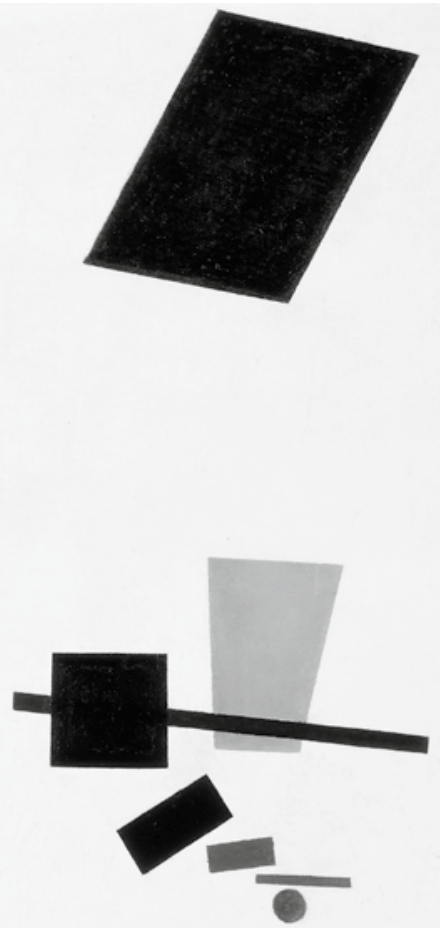

Fig. 8. Malevich, Realismo pictórico de un futbolista - Masas de color en la cuarta dimensión - 1915 


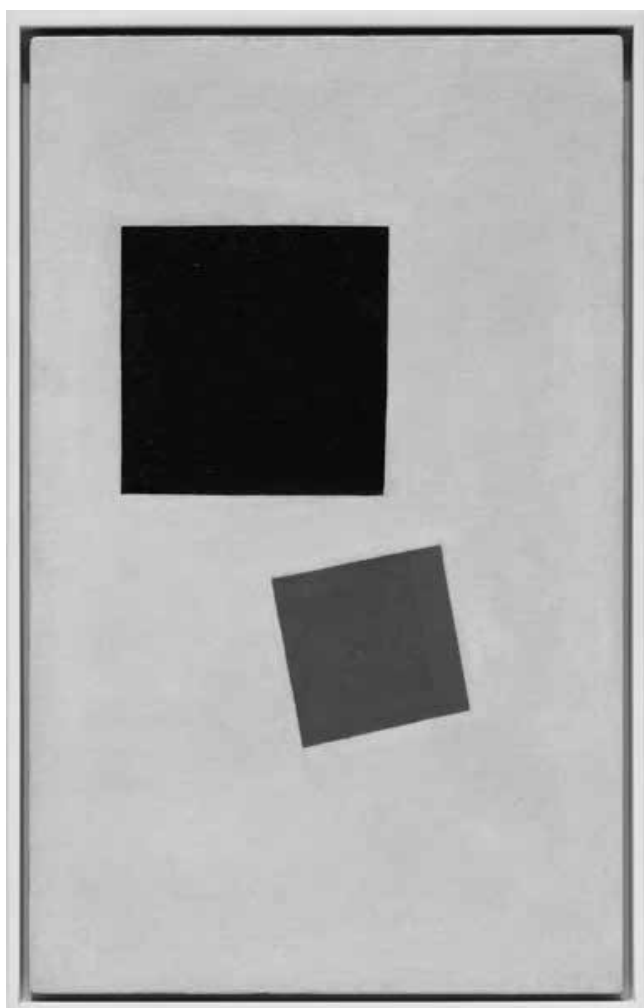

Fig. 9. Malevich, Realismo pictórico de chico con mochila - Masas de color en la cuarta dimensión - 1915

ciendo un esfuerzo visible por representarla y explicarla en base a lo que Ouspensky planteaba:

La expresión cuarta dimensión a menudo se encuentra en el lenguaje usual y en literatura, pero muy raramente alguien tiene una idea clara de lo que realmente significa. Generalmente la cuarta dimensión se utiliza como sinónimo de lo misterioso, lo milagroso, lo sobrenatural, incomprensible e incognoscible, como una especie de definición general de los fenómenos del mundo extra-físico.

Los espiritistas y los ocultistas de varias escuelas a menudo hacen uso de esta expresión en su literatura, asignando a la esfera de la cuarta dimensión todos los fenómenos del mundo del mas allá o de la esfera astral. Pero no explican lo que significa, y por lo que dicen solo puede entenderse que la principal propiedad que atribuyen a la cuarta dimensión es la de la incognoscibilidad. ${ }^{32}$

\section{Para Yevgenia Petrova:}

Malevich estuvo, en esencia, creando un nuevo tipo de icono, a diferencia de los pintores

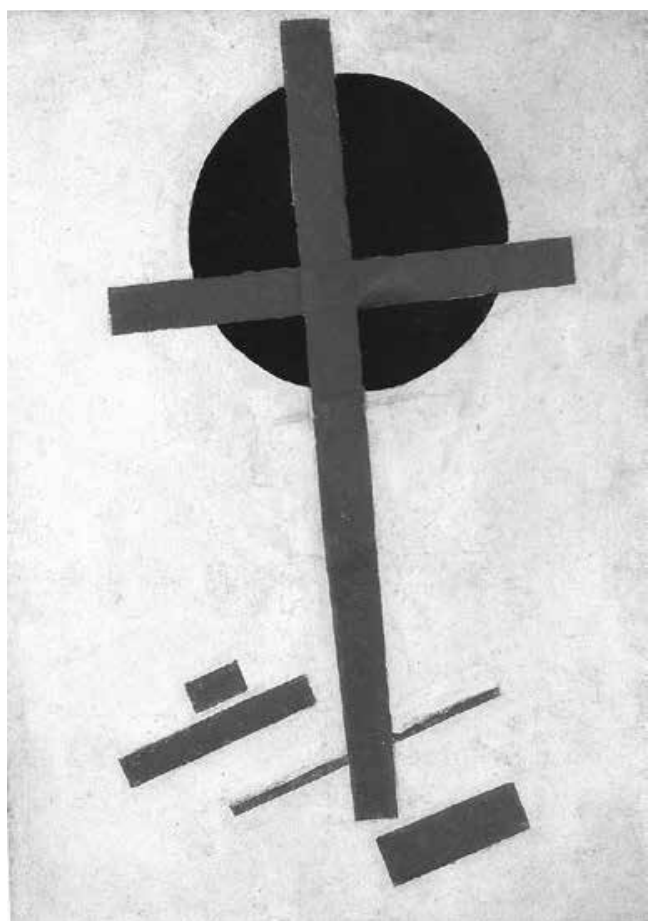

Fig. 10a. Malevich, Cruz roja sobre círculo negro - 1921

rusos ortodoxos de iconos que ilustraban los textos biblicos, sin embargo, Malevich eliminó toda la narrativa de sus composiciones. Minimalizó las imágenes, reduciéndolas a sus formas puras, y monumentalizó los cuadrados, círculos y cruces empleadas por los pintores de iconos en las ropas de los santos, elevándolas al nivel de símbolos independientes y multisignificativo. Al situar un cuadrado, círculo, o cruz sobre un fondo blanco o gris, Malevich estaba retornando a los cánones del arte de la Antigua Rusia, reinterpretándolas en su propia manera original. ${ }^{33}$

En relación con las palabras de Yevgenia Petrova, podemos observar las notables similitudes existentes, por ejemplo, entre la cruz rusa y cuadros como Cruz Roja sobre un Círculo Negro (1921), Suprematismo Místico (Cruz Negra y Óvalo Rojo) (1920-22) Suprematismo (1927), entre otras tantas (Figs. 10a y 10b).

No obstante, uno de los referentes del suprematismo fue el Cuadrado negro, que se opuso al arte naturalista y figurativo, lo que convertía su arte abstracto en un acto puro de creación, una reacción iconoclasta contra el repertorio 


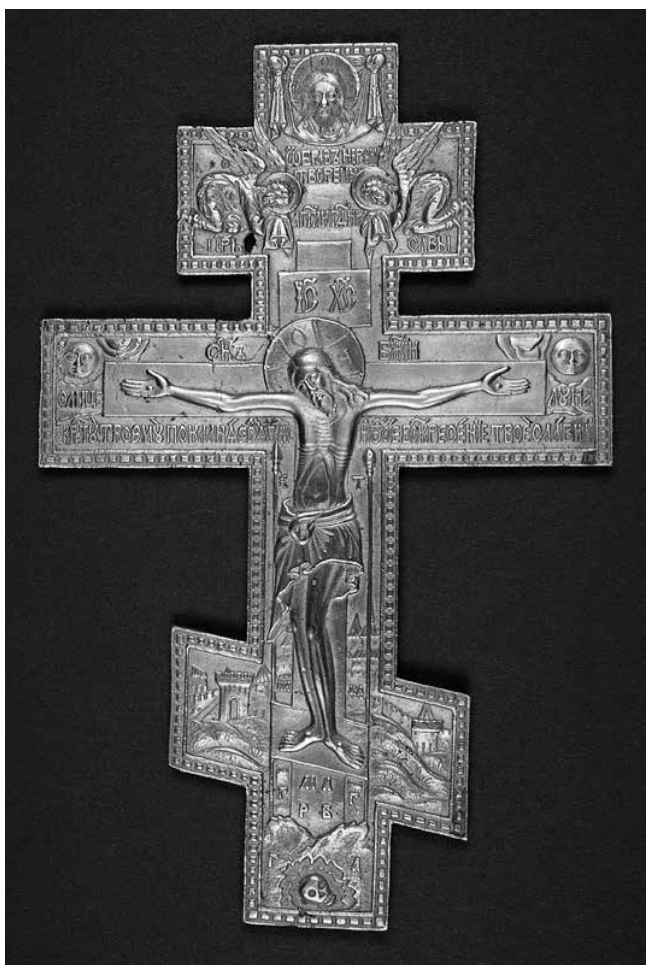

Fig. 10b. Cruz tradicional rusa

formal tradicional. En palabras de José María Faerna: "El bien conocido Cuadrado Negro de 1915, un icono virtual del suprematismo, era el punto final del desarrollo. El cuadrado negro representa la nada y expresa la nada. Es la zona cero de la pintura, una imagen reducida a sus componentes más esenciales, una forma vacía que conlleva la nada pero el sello de la mano del pintor. Tal profundo reduccionismo no podría durar mucho, gradualmente llegaría a un idioma geométrico de formas y colores, que continúan con un incremento de la complejidad a través de derivaciones sucesivas desde el cuadrado elemental" 34 (Fig. 11).

El cuadrado negro 35 no es en si mismo un símbolo nihilista ni debe tener una interpretación negativa, ya que se trata de un plano de ruptura entre la pintura figurativa y la pintura pura, más que la muerte del arte antiguo es el nacimiento de una nueva pintura. Para ello, el suprematismo comenzaba a centrarse en formas geométricas fundamentales, especialmente el círculo y el cuadrado. Para John Golding:

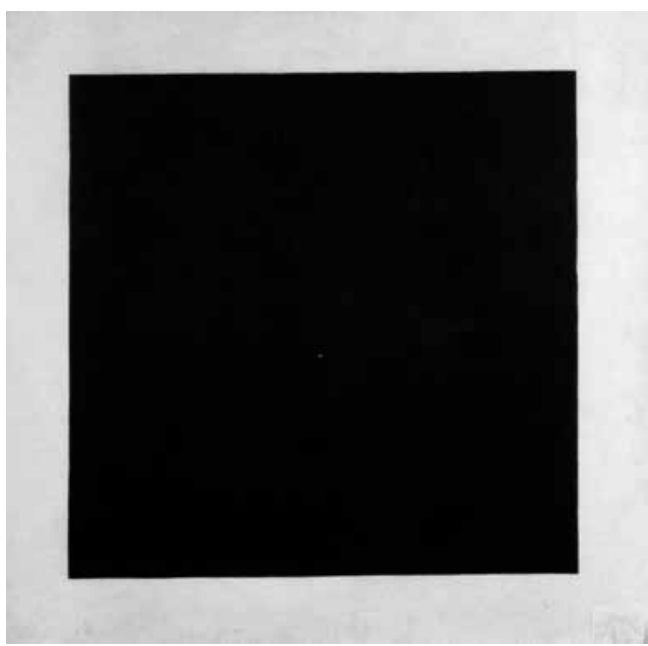

Fig. 11. Malevich, Cuadrado Negro - 1915

Cuando Malevich produjo el Cuadrado negro y las pirotecnias verbales que lo acompañaron, también había sido influido -con frecuencia, indirectamente- por un vasto y amorfo cuerpo de literatura filosófica y especulativa, que abarcaba desde las interpretaciones simbolistas rusas de la ideología del siglo XVIII y principios del XIX hasta la filosofía contemporánea de Bergson, pasando por Nietzsche y Walt Whitman. La superconciencia y los modos de alcanzarla, de M.V. Lodizhenski, que se publicó en 1911, fue particularmente influyente en los círculos del cubofuturismo ruso y el mismo Malevich cayó bajo el embrujo de otros ocultistas y hacia finales del siglo anterior. ${ }^{36}$

Mediante estas abstracciones se intentaba llevar al espectador a una consciencia cósmica, sensación pura y espiritual, relacionándose con la filosofía hiperespacial de Hinton y Ouspensky. De acuerdo a Malevich:

El cuadrado negro sobre fondo blanco fue la primera forma de expresión de la sensibilidad noobjetiva: cuadrado=sensibilidad; fondo blanco $=l a$ Nada, lo que está fuera de la sensibilidad.

$Y$, sin embargo, la mayoría de la gente considera la ausencia de objetos como el final del arte $y$ no reconoce el hecho inmediato de la sensibilidad hecha forma.

El cuadrado de los suprematistas y las formas derivadas de él se pueden comparar a los signos del hombre primitivo, que en su conjunto no querían ilustrar, sino representar la sensibilidad del ritmo. ${ }^{37}$ 
Después de emplear las primeras imágenes en negro y luego en rojo, posteriormente las composiciones se van haciendo más complejas. Malevich fue incrementando el vocabulario de su nuevo idioma, tal y como se puede observar en su cuadro Suprematismo de 1915, donde van apareciendo nuevas formas, lo que genera una mayor tensión compositiva. En Supremus 58 de 1916 (Fig. 12), empieza a combinar otros elementos diferentes, algunos de los cuales son orgánicos, junto con largos planos geométricos. Estas formas aparecen flotando y gravitando en el espacio a modo de espacio etéreo, de hecho, para Matthew Drutt: "Otro trabajo redescubierto, Dissolution of a Plane (1917), es la más grande de las pinturas suprematistas de Malevich, $y$, como tal, tiene una presencia dramática e imponente. Previamente identificada como una de las 24 formas clave en su repertorio suprematista a través de uno de los dibujos para The Nonobjective World, pertenece a la próxima fase del trabajo de Malevich, cuando las composiciones sobre asociaciones mayores con resonancia magnética y acústica y estados de emociones relacionados con forma o existencia etérea ${ }^{38}$.

En las últimas pinturas suprematistas, fue mostrando un interés creciente por las posibilidades de la gradación tonal, tal y como se puede observar en Pintura suprematista de 1917-18.

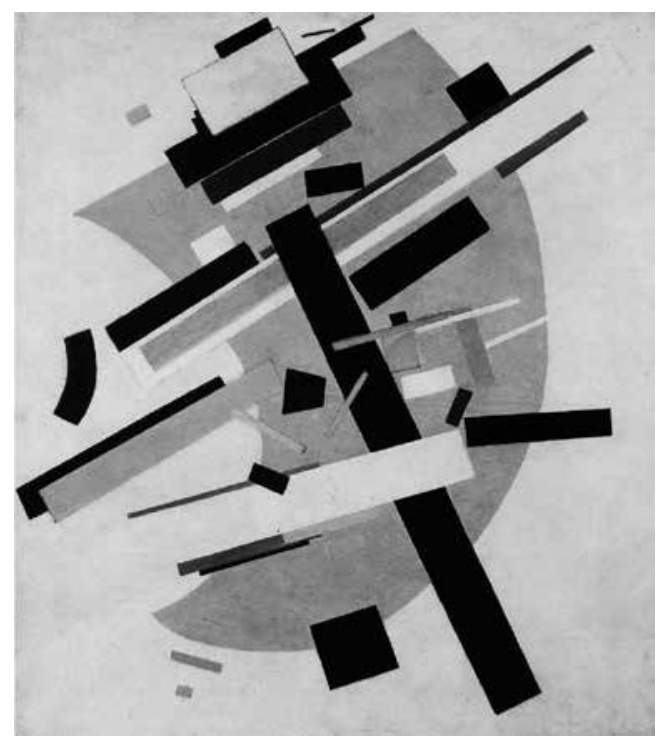

Fig. 12. Malevich, Supremus 58 - 1916
En 1918 Malevich ya afirmaba que el suprematismo había llegado a un nivel superior, que de hecho había logrado el nivel supremo de la inmaterialidad pura. Es decir, la superación de todo rastro figurativo que podía atisbarse todavía en las composiciones multicolores de los años 1915-17. Para Jeannot Simmen y Kolja Kohlhoff, "Malevich no quiere reproducir la realidad en sus cuadros, no pretende representar lo verdadero ni lo objetivo. Busca un arte más allá de la realidad, un universo pictórico carente de objetividad. Para el artista este mundo abstracto empieza más allá del arte académico, que sólo refleja, y del cubismo, que descompone lo que ve." ${ }^{39}$ De ahí, las siguientes frases de Malevich:

Los artistas siempre se sirvieron preferentemente del rostro humano en sus representaciones, porque en él creyeron encontrar la mejor posibilidad de expresar sus propias sensaciones (la mímica multilateral, elástica y plena de expresiones ofrece, en efecto, tales posibilidades). $Y$, sin embargo, los suprematistas han abandonado las representaciones del rostro humano y del objeto naturalista en general, y han buscado signos nuevos para interpretar la sensibilidad inmediata y no los reflejos convertidos en forma de las distintas sensaciones, y ello porque el suprematista no mira ni toca: solamente percibe. ${ }^{40}$

Malevich no tuvo ningún inconveniente en reconciliar la condición plana de sus pinturas con el espacio infinito, ya que gran parte de sus referentes intelectuales, y especialmente los que partían de parámetros místicos de la geometría, planteaban que mediante la eliminación de la representación pictórica tridimensional o ilusionista, se podían representar y explicar esquemáticamente sobre un plano una cuarta dimensión. En torno a esta planitud, el artista comenta lo siguiente:

Desde mi punto de vista, pues, el suprematismo en tanto que superficie plana no existe, el cuadrado es únicamente una de las facetas del prisma suprematista, a través del cual el mundo de los fenómenos se refracta de modo diferente que en el cubismo o en el futurismo, y la apropiación de la luz, o bien del color, o de una forma de construir, es negada totalmente por su conciencia, hasta el punto de un rechazo absoluto por revelar figurativamente las cosas. Estableciendo la no-figuración (bespredmietnost), la conciencia aspira a través 
de ella al absoluto en el que rechaza comprender algo determinado mediante una tensión concreta del pensamiento humano, de la razón, y por el intermedio de la construcción de pantallas solares en las que apareciera definitivamente, de manera clara, cualquiera de los fenómenos del mundo. ${ }^{41}$

En los años 20, la palabra relatividad será habitual en los textos del artista. Durante esta década, se popularizará el mundo espacio-temporal curvo de la Relatividad General, en referencia a Lobachevsky y Riemann, que ya anteriormente el artista ruso había reflejado en trabajos como Suprematismo. (Supremus \#58. Amarillo y Negro) de 1916 y su posterior Suprematismo Místico (Cruz Negra y Óvalo Rojo) de 1920-22.

En los trabajos de Malevich, las formas ladeadas sugieren retroceso hacia adentro, son formas planas frontales que se encuentran en un espacio indeterminado. Malevich estaba imaginando una nueva perspectiva sin perspectiva.

Se ha sugerido que las formas inclinadas que aparecieron por primera vez en la obra de Malevich en 1913-1914 tal vez reflejen los diagramas de Bragdon y las ideas de Uspensy que describían cubos de la cuarta dimensión pasando a través de las pantalla de nuestro espacio cotidiano." 42 Para Malevich, "el suprematismo, pues, abre al arte nuevas posibilidades, ya que, al cesar la llamada consideración por la correspondencia con el objetivo, se hace posible transportar al espacio una percepción plástica reproducida en el plano de una pintura. El artista, el pintor, ya no esta ligado al lienzo, al plano de la pintura, sino que es capaz de trasladar sus composiciones de la tela al espacio. ${ }^{43}$

Aunque son numerosos los planteamientos que se puedan generar a la hora de tratar la cuarta dimensión, todos sus defensores aceptaban que esta representaba un espacio fuera de la percepción sensorial, invirtiendo el sentido en relación con lo que era real e irreal o lógico e ilógico en base a la percepción que tenemos del universo tridimensional, el cual obviamente en estos círculos se consideraba absolutamente ilusorio. Como afirma el propio artista ruso: "La introducción de las cosas en el tiempo muestra, además, una nueva dimensión entre sus diversidades. Desde luego, la cuarta dimensión ha existido siempre, pues todo se encontraba en ella; pero no hemos tomado conciencia de ello hasta ahora. La proporción y el vínculo no están del todo claros, ni siquiera para el técnico y el tornero que van a protestar con todas sus fuerzas contra el cubismo, aunque este último, al trabajar su objeto, lo haga girar y le confiera unas proporciones simplemente a través de la cuarta dimensión." 44

Junto con el interés de Malevich por la geometría y el movimiento, una tercera vía para la filosofía del hiperespacio podía haber sido el espacio libre de gravedad. Por ejemplo, en la pintura Ocho rectángulos rojos (1915) (Fig. 13) su fondo blanco puede ser leído como un espacio blanco infinito y nebuloso en donde las formas flotan libremente. Al alejar las formas del mundo fenoménico y representarlas en el sentido geométrico, Malevich debía haber sentido el encuentro de un nuevo espacio de suprematismo tetradimensional. Auque los trabajos suprematistas monocromáticos y más simples como Ocho rectángulos rojos, pueden ser leídos como secciones de una cruz de figuras en un plano simple, las pinturas más complejas incluyen colores múltiples, como Pintura Suprematista: Trapecio y cuadrado rojo (1915), donde se ve un sentido de proceso (Fig. 14). Las formas se mueven en un espacio que se mueve hacia adelante y hacia atrás. Es aquí quizás donde plantea abordar figuras de cuarta dimensión por medio de sus secciones con menos dimensión. Serían como formas coloreadas a modo de símbolos para cuerpos tridimensionales, moviéndose en una nueva dirección y creando tanto sólidos tetradimensionales como espacio tetradimensional.

El proceso experimental que adoptó Malevich se centraba en pautas reduccionistas, con el objetivo de alcanzar la creación pura, que la definió como el cero de las formas, que perfectamente se ve en la obra Cuadrado blanco sobre fondo blanco (1918) (Fig. 15), un ejemplo claro del grado cero de la pintura, totalmente alejada de cualquier atisbo de representación mimética y objetiva. Ahora, el artista estaba libre del mundo de las apariencias. Esta negación de las apariencias y logro del cero de las formas fue definido por Malevich como un desierto, es decir, un proceso de desertización de todo referente natural. En relación a este último cuadro, Andréi Nakov comenta lo siguiente: "Se trataba de liberar la 


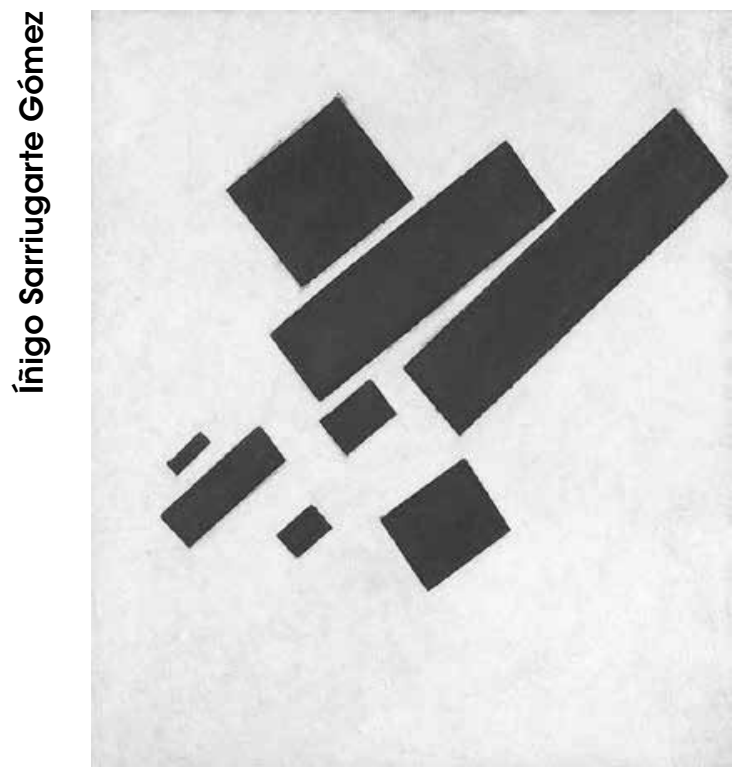

Fig. 13. Malevich, Ocho rectángulos rojos - 1915

pintura de la palabrería para-pictórica y llegar al grado cero (Malevich, 1915) de su esencia, la de una pintura pura, no sujeta a ningún otro sistema semántico que el de sus propios elementos -forma (pura) y color (puro)-. Una vez afirmado el derecho a esta existencia superior (a la antigua esclavitud respecto al mundo exterior) ya no se trataba de justificarse en el terreno de los paralelos literarios o filosóficos preestablecidos, porque precisamente este arte nuevo consolida los fundamentos de su estatus ontológico en su rechazo ${ }^{45}$.

En base a todo este ascetismo que caracteriza ese tipo de pensamiento, Malevich defendió con fuerza la liberación de la nada. Evidentemente, su fuerza de transfiguración está conexionada con la nada positiva y creadora, presentándose como una vacuidad que representa el verdadero ser, aspectos que fueron extraídos de las teorías del Maestro Eckart y del budismo. De este modo, el trabajo Cuadrado blanco sobre fondo blanco se puede relacionar directamente con el sentido de la nada. De acuerdo a Malevich, "lo que llamamos realidad es el infinito que no conoce ni peso, ni medida, ni tiempo, ni espacio, ni absoluto, ni relativo, que nunca se ha trazado con una forma. La realidad no es más re-

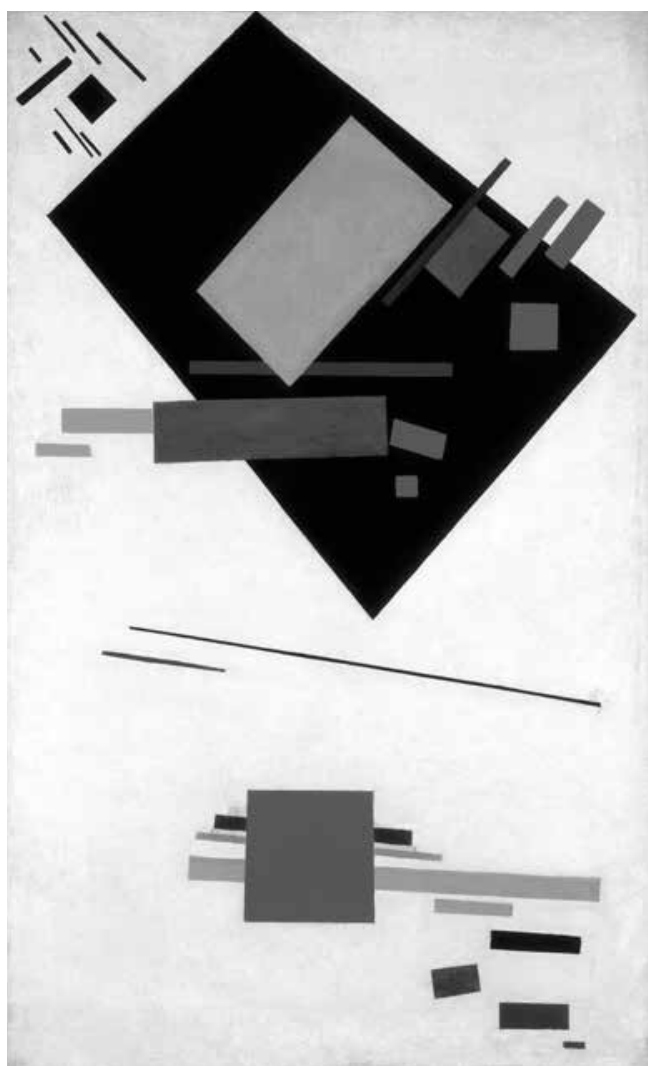

Fig. 14. Malevich, Pintura Suprematista: Trapecio negro y cuadrado rojo - 1915

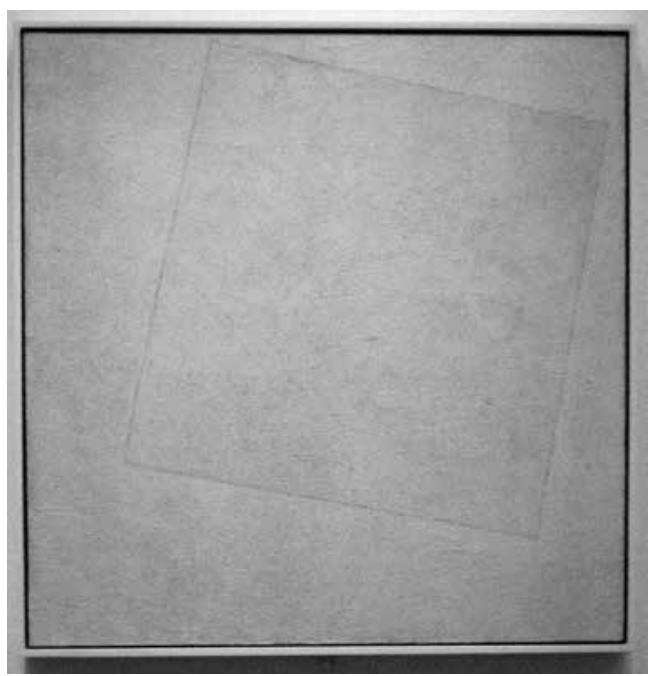

Fig. 15. Malevich, Cuadrado blanco sobre fondo blanco - 1918 
presentable que cognoscible. Nada es cognoscible pero, al mismo tiempo, esa nada eterna existe." ${ }^{46}$ En este sentido, la obra suprematista de Malevich no "se presentaba como nihilista, sino todo lo contrario, como un resultado a partir del cual se podría volver a empezar y pensar todo: la pintura, la escultura, la arquitectura y las artes aplicadas, la escritura; es decir: Hacer tabla rasa, el renacimiento." 47 Pero entendiéndolo como un camino espiritual, tal y como lo explica el propio artista ruso: "Mi pensamiento ha ido a Dios, en tanto que reposo o nada, hacia el lugar donde ya no existen las perfecciones. Pero ¿Cuál es el fin de todas las perfecciones? La perfección es el límite de la nada en marcha, entendida como el reposo, la inacción. Tal debe ser Dios. Si es así, el camino religioso es el de menor resistencia y admite al mismo tiempo la nada del hombre abandonando el algo de Dios." 48

Malevich encuentra en Cuadrado blanco sobre fondo blanco su plenitud filosófica del sistema, centrándolo y relacionándolo con el símbolo místico del cero, despejado desde 1915 por su experiencia pictórica. Para Malevich, al igual que el pensamiento de la filosofía oriental, el cero no es sólo un símbolo matemático ordinario, sino "el depósito o la matriz (garbha) de todo bien y de todos los valores posibles." 49 El cero sería símil de infinito, o dicho de otro modo, la manera en que se representa el infinito se asemejaría al cero, es decir, el Cuadrado blanco sobre fondo blanco. Aquí, se alcanza la plenitud de la nada, la plenitud de la pintura no objetiva. En esta misma línea, Malevich plantea los siguientes postulados:

1. La ciencia y el arte no tienen fronteras porque el objeto del conocimiento es infinito e innumerable, y lo infinito y lo innumerable son iguales a cero.

2. Si todo lo que existe ha sido creado en los caminos del Señor, y esos caminos del Señor son inescrutables el Señor y esos caminos son iguales a cero.

3. Si el mundo ha sido creado por la ciencia, el saber y el trabajo, si su creación es infinita, es igual a cero.

4. Si la religión conoce a Dios, ha conocido el cero.

5. Si la ciencia conoce la naturaleza, ha conocido el cero.

6. Si el arte conoce la armonía, el ritmo y la belleza, ha conocido el cero.

7. Si alguno conoce el absoluto, ha conocido el cero.

8. El ser no existe ni en mí ni fuera de mí, nadie ni nada puede cambiar nada sea lo que sea, porque nada existe que pueda cambiar por sí mismo ni ser cambiado. ${ }^{50}$

En este texto anterior se muestra la forma extrema de su sistema filosófico, donde se reduce todo al estado de una ecuación matemática. El símbolo del cero, que ya había aparecido en sus escritos desde el primer manifiesto de 1915, ahora se convierte en la base del sistema malevichiano. Para Andréi Nakov,

Malevich encuentra un único término de referencia filosófica -la apertura ilimitada del conocimiento místico de la nada (el infinito)-. La comparación de su sistema con la estructura de los sistemas místicos, construidos tanto por el pensamiento occidental como oriental, revela unas similitudes fundamentales y permite ver en el sistema de la pintura no objetiva de Malevich una de las más recientes manifestaciones de ese sistema cero que aparece periódicamente en la historia del pensamiento occidental. Esta puesta en situación de ingravidez intelectual (el grado cero) señala el punto de separación máxima entre el pensamiento europeo y la tendencia oriental a la intuición, la distancia entre la tradición acumulativa del aristotelismo positivo y la causalidad propiamente espiritista (interiormente deductiva y transmisible por la sola experiencia sensorial) de los sistemas espirituales de Oriente. ${ }^{51}$ 


\section{NOTAS}

1 P.D. Ouspensky, Un nuevo modelo del Universo: Principios del método psicológico, Kier, Buenos Aires, 2006, p. 78.

2 Idem, p. 82.

3 P.D. Ouspensky, Tertium Organum: El tercer canón del pensamiento: una clave para los enigmas del mundo, Kier, Buenos Aires, 2004, p. 69.

${ }^{4}$ A. Nakov \& K. Malevich, Escritos, Editorial Síntesis, Madrid, 1996, p. 74.

${ }^{5}$ R. Ibáñez, La cuarta dimensión. ¿Es nuestro universo la sombra de otro?, RBA Coleccionables, Barcelona, 2010, p. 86.

${ }^{6}$ L. Dalrymple Henderson, "The Fourth Dimension and Non-Euclidean Geometry in Modern Art: Conclusion". Leonardo, Vol. 17, No. 3 (1984), p. 205.

7 G. Apollinaire, The Cubist Painters, University of California Press, Berkeley and Los Angeles, California, 2004, p. 16.

${ }^{8}$ Dalrymple, 1984, op. cit., p. 205.

9 J. Golding, Caminos a lo absoluto. Mondrian, Malevich, Kandinsky, Pollock, Newman, Rothko y Still, Turner Publicaciones, Madrid, 2003, p. 59.

${ }^{10}$ Nakov, op. cit., p. 101.

${ }^{11}$ K. Malevich \& A. González García, La luz y el color. Gustavo Gili, Barcelona, 2011, p. 45.

12 J.E. Bowlt, (ed.), Russian Art of the Avant-Garde: Theory and Criticism, 1902-1934, Viking, New York, 1976, pp. 90-91.

${ }^{13}$ R. Kruger, "Art in the Fourth Dimension: Giving Form to Form - The Abstract Paintings of Piet Mondrian". Spaces of Utopia: An Electronic Journal, nr. 5, Summer 2007, pp. 23-35. [Consulta: 14/11/2013] Enlace: http://ler. letras.up.pt/uploads/ficheiros/4351.pdf

${ }^{14}$ B. Russel, A History of Western Philosophy, Unwin, London, 1985, p. 703.
15 Malevich en L. Cirlot, Primeras Vanguardias: textos y documentos, Parsifal Ediciones, Barcelona, 1999, p. 221.

${ }^{16}$ D. Kuspit, Signos de psique en el arte moderno y posmoderno, Akal, Madrid, 2003, p. 142.

${ }^{17}$ Malevich, 2011, op. cit., p. 7.

${ }^{18}$ Nakov, op. cit., p. 10.

${ }^{19}$ Claude Fayette Bragdon (18861946), escritor y arquitecto norteamericano, que trabajó en el campo de la arquitectura, sin realizar estudios formales dentreo de este área. Como arquitecto trabaja en la línea de Louis Sullivan y Frank Lloyd Wright, abogando por un planteamiento teosófico en el diseño del edificio, defendiendo un estilo gótico de carácter más orgánico. Igualmente, desarrolló actividades como diseñador teatral. Colaboró en la fundación de la Logia Genese de la Sociedad Teosófica de Rochester (New York) y en la traducción del Tertium Organum de Ouspensky.

${ }^{20}$ Para más información, remitirse al libro de C.H. Leadbeater, The Other Side of the Death: Scientifically Examined and Carefully Described, Kessinger Publishing, Montana, 1997, páginas 235 y 246-247.

21 L. Dalrymple Henderson, The Fourth Dimension and Non-Euclidean Geometry in Modern Art, Princeton University Press, Princeton, New Jersey, 1983 , p. 45.

22 Ouspensky, 2006, op. cit., p. 97.

${ }^{23}$ L. Revel, "L'Esprit et l'espace: La Quatriéme Dimension". Le Théosophe, marzo de 1911, p. 2.

${ }^{24}$ Ouspensky, 2006, op. cit., p. 82.

${ }^{25}$ Nakov, op. cit., p. 101.

${ }^{26}$ Golding, op. cit., p. 62.

27 Malevich en L. Cirlot, op. cit., pp. 229-230.

28 J.M. Faerna, (ed.), Malevich, Cameo/Abrams, New York, 1996, p. 6.

${ }^{29}$ Nakov, op. cit., p. 79.

${ }^{30}$ K. Malevich \& A. Nakov, Escritos, Editorial Síntesis, Madrid, 1996, p. 272.
${ }^{31}$ Idem, p. 291.

32 Ouspensky, 2006, op. cit., p. 77.

33 Y. Petrova, "Malevich's Suprematism and Religion" en Kazimir Malevich: Suprematism, (Mathew Drutt, Coord.), The Solomon R. Guggenheim Foundation, New York, 2003, p. 91.

${ }^{34}$ Faerna, op. cit., p. 6.

35 Posteriormente, en 1935, Suetin diseñó un cubo blanco de madera con un cuadrado negro que se deterioró con el tiempo. Más adelante, el propio Malevich sería enterrado en un ataúd suprematista preparado expresamente para él. En la actualidad, sus cenizas reposan en un cubo situado en Leningrado; se trata de un cubo blanco de hormigón, quedando el cuadrado frontal recubierto de rojo carmesí.

${ }^{36}$ Golding, op. cit., p. 61.

${ }^{37}$ Malevich, en L. Cirlot, op. cit., p. 224.

38 M. Drutt, "Kazimir Malevich: Suprematism" en Kazimir Malevich: Suprematism, (Mathew Drutt, Coord.), The Solomon R. Guggenheim Foundation, New York, 2003, p.8.

39 J. Simmen \& K. Kohlhoff, Kasimir Malevich. Vida y obra, Könemann Verlagsgesellschaft, Colonia, 1999, p. 43.

${ }^{40}$ Malevich, en L. Cirlot, op. cit., pp. 228-229

${ }^{41}$ Malevich, 2011, op. cit., p. 21.

${ }^{42}$ Golding, op. cit., p. 70.

${ }^{43}$ Malevich, en L. Cirlot, op. cit., p. 231.

${ }^{44}$ Malevich, 2011, op. cit., pp. 45-46.

${ }^{45}$ Nakov, op. cit., p. 21.

${ }^{46}$ Malevich, 1996, op. cit., p. 431.

${ }^{47} \mathrm{G}$. Néret, Malevich 1878-1935 y

el suprematismo, Taschen, Köln, 2003, p. 50.

${ }^{48}$ Malevich, 1996, op. cit., p. 450.

${ }^{49}$ Nakov, op. cit., p. 150.

50 Malevich, 1996, op. cit., pp. 299-300.

${ }^{51}$ Nakov, op. cit., p. 42. 